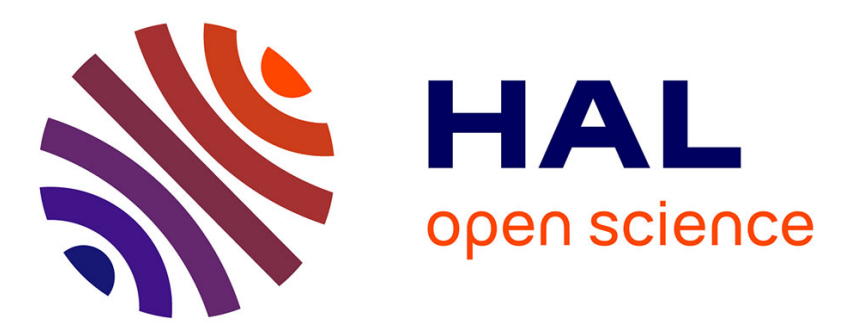

\title{
Investigation of fatty acids accumulation in Nannochloropsis oculata for biodiesel application.
}

G. van Vooren, Fabienne Le Grand, J. Legrand, S. Cuiné, G. Peltier, Jeremy Pruvost

\section{- To cite this version:}

G. van Vooren, Fabienne Le Grand, J. Legrand, S. Cuiné, G. Peltier, et al.. Investigation of fatty acids accumulation in Nannochloropsis oculata for biodiesel application.. Bioresource Technology, 2012, 124, pp.421-32. 10.1016/j.biortech.2012.08.009 . hal-00788607

\section{HAL Id: hal-00788607 \\ https://hal.univ-brest.fr/hal-00788607}

Submitted on 14 Apr 2020

HAL is a multi-disciplinary open access archive for the deposit and dissemination of scientific research documents, whether they are published or not. The documents may come from teaching and research institutions in France or abroad, or from public or private research centers.
L'archive ouverte pluridisciplinaire HAL, est destinée au dépôt et à la diffusion de documents scientifiques de niveau recherche, publiés ou non, émanant des établissements d'enseignement et de recherche français ou étrangers, des laboratoires publics ou privés. 


\title{
Investigation of fatty acids accumulation in Nannochloropsis oculata for biodiesel application
}

\author{
G. Van Vooren ${ }^{\mathrm{a}}$, F. Le Grand ${ }^{\mathrm{b}}$, J. Legrand ${ }^{\mathrm{b}}$, S. Cuiné ${ }^{\mathrm{c}}$, G. Peltier ${ }^{\mathrm{c}}$, J. Pruvost ${ }^{\mathrm{a}, *}$ \\ a Université de Nantes, CNRS, GEPEA, UMR-CNRS 6144, bd de l'Université, CRTT-BP 406, 44602 Saint-Nazaire Cedex, France \\ ${ }^{\mathrm{b}}$ LEMAR, UMR 6539, Institut Universitaire Européen de la Mer, Place Nicolas Copernic, Technopôle Brest-Iroise, 29280 Plouzané, France

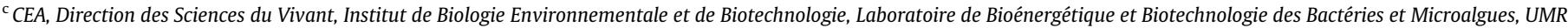 \\ Biologie Végétale et Microbiologie Environnementale CEA-CNRS-Aix Marseille Université, CEA Cadarache, Saint-Paul-lez-Durance F-13108, France
}

\section{H I G H L I G H T S}

- Analysis of lipids accumulation in photobioreactors for Nannochloropsis oculata.

- Discussion of FA profiles evolution with respect to biodiesel criteria.

- Role of light received per cell and nitrogen starvation strategy.

\begin{abstract}
A B S T R A C T
Lipids production of the marine microalga species Nannochloropsis oculata was deeply investigated by studying under continuous light the effects of different nitrogen starvation strategies in photobioreactors of various thicknesses. Operating parameters like incident photons flux density (PFD), initial nitrogen (progressive starvation strategy) or biomass concentrations (sudden starvation strategy) were examined, with a detailed analysis of their effects on the quality and production kinetics of total (TL) and triglycerides (TG).

In addition to the already known effect of nitrogen starvation to trigger reserve lipids accumulation (mainly TG), it was demonstrated the relevance of the light received per cell affecting TG content and productivities, as well as fatty acids (FA) profiles. With appropriate optimization, N. oculata was confirmed as an interesting candidate for biodiesel application, with high FA accumulation (up to around 50\%DW with $43 \% \mathrm{DW}$ in TG-FA), high productivity (maximum $3.6 \times 10^{-3} \mathrm{~kg}_{\mathrm{TG}-\mathrm{FA}} \mathrm{m}^{-2} \mathrm{~d}^{-1}$ ) and a TG-FA profile close to palm oil.
\end{abstract}

\section{Introduction}

Microalgae are considered as an alternative to vegetable oils for biodiesel production (Chisti, 2007). Their main advantages are high biomass surface productivity and high lipids content, the possibility of consumption of inorganic carbon issued from industrial flue gas, and production in closed systems (photobioreactors - PBR), offering several advantages including an intensified, controlled production with very low environmental impact (no fertilizer is released and water can be re-used). However, a lot of challenges/problems have to be overcome/solved before allowing large-scale microalgae production. For example, it is necessary to develop competitive and sustainable exploitation systems (Pruvost, 2011; Wijffels and Barbosa, 2010), and to select appropriate

\footnotetext{
* Corresponding author. Tel.: +33 (0)2 401726 69; fax: +33 (0)2 40172618.

E-mail address: jeremy.pruvost@univ-nantes.fr (J. Pruvost).
}

microalgae strain/species combining features affecting in a positive manner any step of the global process from biomass production to lipids extraction and valorization as biofuel (Rodolfi et al., 2009).

Lipids productivity is obviously a key-aspect but lipids quality must also be in accordance with the targeted biofuel. To be used as biodiesel, microalgae lipids fatty acids (FA) need to be esterified or transesterified (Chisti, 2007). Esterification is an energy consuming reaction due to the formation of an ester linkage while transesterification requires only an exchange of a pre-existent ester linkage. Transesterification is thus the most common process to produce biodiesel from vegetable oils. An acid or a basic catalyst is needed for reaction completion, basic catalyst leading however to a less energy consuming process (Chisti, 2007; Vicente et al., 1998). In both cases, transesterification reaction leads to free methanol and glycerol releases, implying a further separation step to recover the new-synthesized fatty acid methyl esters 
(FAMEs) to be used as biofuel. However, lipids composition can hinder this separation step. Free fatty acids form soaps with the basic catalyst, and phospholipids and glycolipids act as surfactants. In addition, biodiesel must fulfill specific norms (ASTM D 6751-09 or DIN EN 14214) that limit the presence of free fatty acids and phosphorus, making actual industrial transesterification process restricted to a part of total fatty acids (TL-FA), namely those issued from pure triacylglycerol (TG-FA). But, even in this case, TG-FA quality is constrained due to the need of a low sensitivity to oxidation for prolonged storage. This sensitivity is correlated to the FA unsaturation and especially polyunsaturated fatty acids (PUFA) which are, in this context, not ideal for biodiesel application. For example, DIN EN 14214 norm fixes a limit in PUFA content to $1 \%$ maximum.

Both FA productivity and quality are species dependent on, in a general manner, marine species being known as having a high PUFA content (Spolaore et al., 2006). Cultivation conditions are also known to be highly relevant. Nitrogen starvation is especially wellknown to increase microalgae lipids contents in favour of TG-FA (Tornabene et al., 1983). Nitrogen starvation can be practically conducted in two ways. Sudden starvation is obtained by re-suspending after separation previously grown cells in a nitrogen-free cultivation medium. Progressive starvation consists in inoculation of microalgae in a medium containing limited nitrogen content, nitrogen consumption during culture growth leading then to a natural nitrogen-starvation (please refer to Pruvost et al., 2009, 2011b for a detailed description). In practice, progressive starvation appears more suitable, as it does not imply a separation step which implementation at large-scale would certainly result in a significant energy demand. But, as already shown by authors for Neochloris oleoabundans (Pruvost et al., 2009), progressive starvation also results in a more complex response, as the progressive increase in biomass concentration also affects light transfer conditions, which in turns could affect the photosynthetic response and lipids accumulation.

Aim of the present study is to investigate in details the effects of nitrogen starvation on an oil-producing marine microalgae Nannochloropsis oculata known for its potential interest in biodiesel production (Rodolfi et al., 2009; Sheehan and Dunahay, 1998; Shifrin and Chilsholm, 1981). For that purpose, $N$. oculata was cultivated under continuous light in various PBRs. Both progressive and sudden nitrogen starvations protocols were investigated. Characterization was conducted on biomass, pigments and FA, with a detailed analysis of TL-FA and TG-FA production kinetics. Respective effects of the starvation process (progressive vs. sudden), of the PBR thickness, of the initial nitrogen level (progressive starvation) or initial biomass (sudden starvation), and of the incident photons flux density (PFD) were examined.

\section{Methods}

\subsection{Strain, PBR and cultures}

Nannochloropsis oculata strain and $0.2 \mu$ filtered seawater were obtained from Alphabiotech collection (Asserac, France). Seawater salinity was adjusted at $25 \mathrm{~g} / \mathrm{l}$ measured with refractometer and sterilised $25 \mathrm{~min}$ at $125^{\circ} \mathrm{C}$. A modified Conway medium with three fold nitrate and phosphate (noted 3N3S) enrichments was sterilised $25 \mathrm{~min}$ at $125^{\circ} \mathrm{C}$ and added in seawater at $3 / 1000$.

A flat $1 \mathrm{~L}$ airlift PBR was used in continuous mode (chemostat) to produce biomass with constant biochemical composition used then for all nitrogen starvation experiments (described next). $\mathrm{pH}$ and temperature were automatically regulated at 8.0 by $\mathrm{CO}_{2}$ injection and $25^{\circ} \mathrm{C}$ by ambient air blowing respectively. The incident light flux $q_{\mathrm{o}}$ (or PFD, i.e. photons flux density) was provided by a set of eight fluorescent white tubes so as to obtain a constant PFD of $160 \mu$ mole $\mathrm{m}^{-2} \mathrm{~s}^{-1}$. The dilution rate was $D=0.43 \mathrm{~d}^{-1}$ allowing to obtain a biomass dry weight (DW) concentration in the harvest of $0.85 \mathrm{~kg} \mathrm{~m}^{-3}$ (biomass volumetric productivity of $\left.0.365 \mathrm{~kg} \mathrm{~m}^{-3} \mathrm{~d}^{-1}\right)$.

Nitrogen deprivation experiments were conducted in batch mode in two different PBR types. The first one was similar to the one used to produce biomass ( $1 \mathrm{~L}$, flat panel airlift, depth of culture of $0.03 \mathrm{~m}$ ) except for the light source which was supplied by a LED panel to facilitate PFD adjustment (P4 Cool White LED, Seoul SemiConductor, Korea). In order to investigate the effect of PBR thickness (e) and to allow a higher sampling rate, a PBR of higher volume ( $130 \mathrm{~L}$, flat panel airlift, depth of culture of $0.055 \mathrm{~m}$ ) was used. More details (PBR description, Conway medium composition) can be found in Pruvost et al. (2011b).

For progressive starvation experiments, PBR was filled with a mixture of 3N3P Conway medium and nitrogen free Conway medium (-N medium) to reach the requested initial nitrogen concentration $\left(\mathrm{N}_{\mathrm{o}}\right)$. The PBR was then inoculated with $0.06 \mathrm{~L}$ of the harvest of the PBR operated in continuous chemostat mode. For sudden starvation experiments, a volume of culture from the PBR in continuous mode was collected and centrifuged $5 \mathrm{~min}$ at $1600 \mathrm{~g}$. Supernatant was eliminated and replaced by the $-\mathrm{N}$ medium. Volume of culture to be centrifuged was chosen depending on the initial biomass $\left(D_{\mathrm{o}}\right)$ needed for the experiment. In all experiments, medium concentration was adjusted and $10 \mathrm{mM}$ of sodium bicarbonate were added to avoid mineral (except nitrogen when needed) and carbon limitation respectively. Fourteen experiments were conducted and four parameters were tested: type of nitrogen deprivation (progressive or sudden), initial nitrogen (progressive deprivation) or biomass concentrations (sudden deprivation), PBR thickness and PFD. All conditions are summarized in Table 1.

Table 1

Description of nitrogen starvation experiments.

\begin{tabular}{|c|c|c|c|c|c|c|}
\hline $\begin{array}{l}\text { Experiments } \\
\text { number }\end{array}$ & $\begin{array}{l}\text { Nitrogen } \\
\text { deprivation protocol }\end{array}$ & $\begin{array}{l}\text { PFD } \\
\left(\mu \text { mole } \mathrm{m}^{-2} \mathrm{~s}^{-1}\right)\end{array}$ & $\begin{array}{l}\text { Initial nitrogen }\left(N_{0}\right) \\
\text { or biomass }\left(\mathrm{DW}_{\mathrm{o}}\right) \text { concentrations }\end{array}$ & $\begin{array}{l}\text { PBR } \\
\text { thickness }(e)\end{array}$ & $\begin{array}{l}\text { Beginning of } \\
\text { nitrogen starvation }(h)\end{array}$ & $\begin{array}{l}\text { Experiment } \\
\text { duration }(\mathrm{h})\end{array}$ \\
\hline 1 & Progressive & 160 & $\mathrm{~N}_{\mathrm{o}}=0.99 \mathrm{mM}$ & $0.03 \mathrm{~m}$ & 72 & 168 \\
\hline 2 & Progressive & 160 & $\mathrm{~N}_{\mathrm{o}}=1.65 \mathrm{mM}$ & $0.03 \mathrm{~m}$ & 72 & 168 \\
\hline 3 & Progressive & 160 & $\mathrm{~N}_{\mathrm{o}}=2.30 \mathrm{mM}$ & $0.03 \mathrm{~m}$ & 72 & 168 \\
\hline 4 & Progressive & 250 & $\mathrm{~N}_{\mathrm{o}}=0.99 \mathrm{mM}$ & $0.03 \mathrm{~m}$ & 72 & 168 \\
\hline 5 & Progressive & 250 & $\mathrm{~N}_{\mathrm{o}}=1.65 \mathrm{mM}$ & $0.03 \mathrm{~m}$ & 72 & 168 \\
\hline 6 & Progressive & 250 & $\mathrm{~N}_{\mathrm{o}}=2.30 \mathrm{mM}$ & $0.03 \mathrm{~m}$ & 72 & 168 \\
\hline 7 & Progressive & 250 & $\mathrm{~N}_{\mathrm{o}}=2.96 \mathrm{mM}$ & $0.03 \mathrm{~m}$ & 96 & 288 \\
\hline 8 & Progressive & 250 & $\mathrm{~N}_{\mathrm{o}}=3.61 \mathrm{mM}$ & $0.03 \mathrm{~m}$ & 96 & 192 \\
\hline 9 & Progressive & 250 & $\mathrm{~N}_{\mathrm{o}}=0.93 \mathrm{mM}$ & $0.05 \mathrm{~m}$ & 64 & 192 \\
\hline 10 & Progressive & 250 & $\mathrm{~N}_{\mathrm{o}}=1.65 \mathrm{mM}$ & $0.05 \mathrm{~m}$ & 114 & 288 \\
\hline 11 & Sudden & 250 & $\mathrm{DW}_{\mathrm{o}}=0.23 \mathrm{~kg} \mathrm{~m}^{-3}$ & $0.03 \mathrm{~m}$ & 0 & 96 \\
\hline 12 & Sudden & 250 & $\mathrm{DW}_{\mathrm{o}}=0.41 \mathrm{~kg} \mathrm{~m}^{-3}$ & $0.03 \mathrm{~m}$ & 0 & 96 \\
\hline 13 & Sudden & 250 & $\mathrm{DW}_{\mathrm{o}}=0.62 \mathrm{~kg} \mathrm{~m}^{-3}$ & $0.03 \mathrm{~m}$ & 0 & 120 \\
\hline 14 & Sudden & 250 & $\mathrm{DW}_{\mathrm{o}}=0.76 \mathrm{~kg} \mathrm{~m}^{-3}$ & $0.03 \mathrm{~m}$ & 0 & 144 \\
\hline
\end{tabular}




\subsection{Culture analysis}

All analyses were done in triplicate. Algal dry weight (DW) concentration was determined by filtration through a pre-dried and pre-weighed glass-fibre filter (Whatman GF/F). The filter was dried $24 \mathrm{~h}$ at $105^{\circ} \mathrm{C}$, cooled in a desiccator and then weighed again.

Pigments content was determined using a spectrophotometric method as previously described (Pruvost et al., 2011b). Ratio of absorbance at $480 \mathrm{~nm}$ (which is related to carotenoids) and at $665 \mathrm{~nm}$ (which is related to chlorophylls) was also measured. As shown in the study, this revealed to be directly correlated to pigments degradation as a direct effect of nitrogen deprivation (Flynn et al., 1993).

Nitrate and phosphate concentrations were measured using anionic chromatography (DIONEX-ICS 900 - IonPac equipped with a AS9HC anionic column and an external ASRS supplied with sulphuric acid $25 \mathrm{mM}$ ) and standards. Eluant was a solution of $9 \mathrm{mM} \mathrm{Na}_{2}$ $\mathrm{CO}_{3}$ with a flow of $0.9 \mathrm{ml} / \mathrm{mn}$ at ambient temperature.

\subsection{Lipid analysis}

Lipids analysis being not trivial, eventually depending on the species investigated (especially with species like $N$. occulata having hard cell wall making lipids extraction difficult), three different methods were compared prior to investigations, namely (1) Bligh\&Dyer extraction method followed by High Performance-Thin Layer Chromatography (HP-TLC) analysis, (2) Folch extraction method followed by Gas Chromatography-Flame Ionization Detector (GC-FID) analysis, and (3) whole cell analytic (WCA) method followed by GC-FID analysis. Folch and Bligh\&Dyer extraction methods can be found in Pruvost et al. (2011b) and Siaut et al. (2011), respectively.

\subsubsection{Lipids extraction by the "whole cell" analytic (WCA) method and GC-FID analysis}

Grade solvents were purchased from VWR International. Butylated hydroxytoluene (BHT), boron trifluoride $\left(\mathrm{BF}_{3}, 14 \%\right.$ by weight in methanol), glyceryl triheptadecanoate (TG17:0) and 37 components FAME were obtained from Sigma-Aldrich. Glassware was heated $6 \mathrm{~h}$ at $450{ }^{\circ} \mathrm{C}$ to prevent from organic pollution.

Three $2 \mathrm{~mL}$-replicates of microalgae culture were sampled in glass vials and centrifuged $10 \mathrm{mn}$ at $3600 \mathrm{~g}$ and $4{ }^{\circ} \mathrm{C}$. Supernatant was removed and cells were re-suspended in $6 \mathrm{~mL}$ of a chloroform/methanol mixture $(2 / 1, v / v)$. To ensure a complete lipid extraction, vials were sonicated in a water bath and maintained $6 \mathrm{~h}$ under agitation.

After adding $0.01 \% \mathrm{w} / \mathrm{w}$ of BHT as antioxidant, total lipid (TL) extracts were evaporated to dryness, recovered with $1 \mathrm{~mL}$ of a chloroform/methanol mixture $(2 / 1, \mathrm{v} / \mathrm{v})$ and stored at $-20{ }^{\circ} \mathrm{C}$ under nitrogen before analysis. This WC extraction containing total lipids (TL) was used for analysing the quantity and the quality of both TL-FA and TG-FA by GC-FID.

TG were isolated from TL by solid phase extraction (SPE) as follows. A $100 \mu \mathrm{L}$ aliquot of the $1 \mathrm{~mL}$ TL extract was evaporated to dryness after addition of $10 \mu \mathrm{g}$ of TG17:0, recovered with $500 \mu \mathrm{L}$ and two washing of $250 \mu \mathrm{L}$ of amylene stabilized chloroform, sonicated for $30 \mathrm{~s}$, vortexed and deposited at the top of a silica gel microcolumn (internally produced, $70 \mathrm{~mm} \times 5 \mathrm{~mm}$ i.d., silica gel Kiesegel Merck 70-230 mesh previously heated at $450{ }^{\circ} \mathrm{C}$ and deactivated with $6 \%$ water by weight). TG were eluted with $8 \mathrm{~mL}$ of amylene stabilized chloroform and stored at $-20^{\circ} \mathrm{C}$ under nitrogen before further TG-FA identification and quantification by GC.

Before TL-FA and TG-FA GC-FID analysis, both TL and TG were transesterified. Transesterification reaction was conducted on a $100 \mu \mathrm{L}$ aliquot of the total lipid extract to which $10 \mu \mathrm{g}$ of TG17:0 was added as an internal standard, and on the totality of the previ- ously SPE isolated TG (approximately $8 \mathrm{~mL}$ ), respectively for TL and TG. After evaporation to dryness under nitrogen and addition of $1 \mathrm{~mL}$ of $\mathrm{BF}_{3}$, fractions were heated $10 \mathrm{mn}$ at $100^{\circ} \mathrm{C}$. After cooling and adding $1 \mathrm{~mL}$ of hexane, the organic phase containing FAME was washed three times with $1.5 \mathrm{~mL}$ of water-saturated hexane. FAME were then recovered and analysed with a gas chromatograph (Thermo Focus) equipped with an on-column injector, a TR-FAME capillary column (Thermo-Fisher) and a flame ionization detector. FAMEs were identified by their retention time with known standard mixtures such as the 37-components FAME. FAME quantities were determined from their respective peaks area to the peak area of TG17:0 internal standard. Integration and calculation were done with the software program ChromCard 2.4.1 (Thermo-Fisher).

\subsubsection{Quantification of oil content by High Performance-Thin Layer Chromatography (HP-TLC)}

After Bligh\&Dyer extraction (Siaut et al., 2011), TG were quantified by densitometry following separation using a HP-TLC machine (Camag autosampler 5, Camag, Switzerland). A standard curve of TG17:0 standard was used for quantification. Around $0.5 \mu \mathrm{g}$ of lipid extracts were loaded onto silica gel 60 F254 plates by autosampler, then developed using a solvent mixture (hexane/ diethyl ether/acetic acid: $17 / 3 / 0.2 \mathrm{v} / \mathrm{v} / \mathrm{v}$ ) and colorized with a modified $\mathrm{CuSO}_{4}$ reagent $\left[\mathrm{CuSO}_{4}(20 \mathrm{~g})\right.$, methanol $(200 \mathrm{~mL}), \mathrm{H}_{2} \mathrm{SO}_{4}$ $\left.(8 \mathrm{~mL}), \mathrm{H}_{3} \mathrm{PO}_{4}(8 \mathrm{~mL})\right]$ for $6 \mathrm{~s}$ followed by heating the plate at $141^{\circ} \mathrm{C}$ for $30 \mathrm{~min}$, then scanned with the built-in scanner.

The FA composition was then analysed by GC-FID. FAMEs were prepared using C17:0 TG-FA as an internal standard, and FAMEs were then quantified with a GC-FID (Thermo Fisher Scientific) following separation on a polar TR-WAX column (30 $\mathrm{m} \times 0.25 \mathrm{~mm} \times 0.25 \mu \mathrm{m}$; Thermo Fisher Scientific, San Jose, CA, USA). GC conditions were: split mode injection (1:5) with flame ionization detector temperature $\left(250^{\circ} \mathrm{C}\right)$; oven temperature pro-

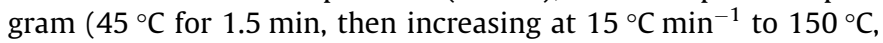
then again increasing to $240{ }^{\circ} \mathrm{C}$ at $6{ }^{\circ} \mathrm{C} \mathrm{min}{ }^{-1}$ and holding at this temperature for $3 \mathrm{~min}$. To quantify the fatty acid composition of triacylglycerol fraction, TG-FA was recovered after separation of the total lipid extraction on TLC (as mentioned above), and lipids revealed by spraying with a primuline dye $(0.005 \%$ in $80 \%$ acetone) visualized under UV light. The co-responding TG-FA fraction on the TLC plate were scrapped off the TLC plate, and packed into a Pasteur pipette staffed with glass wool. TG-FA were eluted with a mixture of chloroform/methanol/ $\mathrm{H}_{2} \mathrm{O}(5 / 5 / 1 \mathrm{v} / \mathrm{v} / \mathrm{v})$ followed by final rinse with hexane. The solvent mixture was kept in a glass tube with a Teflon-lined screw cap, dried under a stream of $\mathrm{N}_{2}$, and fatty acid methyl esters (FAMEs) were prepared and quantified.

\section{Results and discussion}

\subsection{Validation of the "whole cell" analytic (WCA) method for FA quantification}

The two most commonly used methods for total lipid content extraction were described by Bligh and Dyer (1959) and Folch et al. (1957), both followed by a lipid quantification consisting to weight a lipid extract. However, extraction can also be followed by a GC analysis, which is the standard analysis for FA identification and quantification (Christie, 1989). One major limitation is in the weighting of extracts that requests significant culture volumes to be accurate, then it is necessary to limit the sampling rate especially on small scales systems like laboratory PBR (with volume less than $20 \mathrm{~L}$ in general). The WCA method (Meier et al., 2006) limits the sampling volume to the amount needed for GC analysis.

Validation of the WCA method was done on two strains (Chlamydomonas reinhardtii and $N$. oculata) by comparing with the two 
other methods previously described (Folch extraction combined to GC-FID, Bligh\&Dyer combined to HP-TLC). Because extraction ability is an important aspect of the protocol, a first comparison was made in terms of extraction yields. Compared to Folch and Bligh\&Dyer protocols, WCA method gave results superior of $20 \%$ and $16 \%$, respectively in terms of extracted TL-FA. Extracts were then analysed and FA profiles were found similar (results not shown). WCA method was thus considered validated and used for this study (small sampling volume enabling high sampling rate in PBR experiments, high yield of TL extraction on $N$. oculata). It must be noticed that WCA method suffers from sensitivity to pollution due to the small quantities involved ( $200 \mu \mathrm{g}$ lipids), and it must thus be applied with care. Neutral lipids using SPE separations also request attention regarding the chloroform stabilizer. Usual chloroform stabilizer is ethanol at $0.5-1 \%$ but the polarity of ethanol hinders the separation of neutral lipids on silica. Amylene which is neutral has to be chosen as stabilizer but because of its instability and light sensitivity, bad storage conditions can affect directly lipids measurements.

\subsection{Effect of nitrogen deprivation on growth and pigments evolutions}

A typical result of sudden starvation is given in Fig. 1a. It is characterized by one typical growth phase, with more than a threefold increase of DW concentration in $96 \mathrm{~h}$ of cultivation and a simultaneous chlorophyll concentration decrease at the beginning of experiments. Progressive starvation (Fig. 1b) leads to two distinct phases, with (i) a standard growth characterized by an increase in chlorophyll and DW concentrations until total consumption of nitrogen source which occurs in first $100 \mathrm{~h}$, followed by (ii) a typical response to nitrogen starvation, with chlorophyll content decrease and lowered DW concentration increase. It must be noticed that those features were already observed in Pruvost et al. (2009) for the freshwater species Neochloris oleoabundans.

The decrease of chlorophyll content during nitrogen starvation is often explained by the role of chlorophyll as internal nitrogen storage. Photoadaptation process (Josrgensen, 1969) can also be involved, as a direct result of nitrogen starvation which reduces and stops cell division, limiting thus the electrons demand (Goericke and Welschmeyer, 1992). Whatever the case, as already discussed by authors (Pruvost et al., 2009, 2011b), the decrease in chlorophyll content during nitrogen starvation should also certainly have a negative impact on TG-synthesis as it reduces photons absorption and thus photosynthetic activity.

In contrary to chlorophyll content, carotenoids content stays almost constant during starvation. This allows introducing a simple indicator of nitrogen starvation effect on cells defined by the ratio of absorbances at 480 and $665 \mathrm{~nm}$ which are proportional to carotenoïds (Strickland and Parsons, 1968) and chlorophyll (Ritchie, 2006) contents, respectively. This ratio is named in the following "stress factor". In standard growth conditions, a value around $0.55-0.60$ is observed for $N$. oculata, with an increase to more than 2 in nitrogen starvation conditions. If all experiments are com- pared (data not shown), higher values are obtained when diminishing initial nitrogen (Exp. 4, 5, 6, 7) or DW concentration (Exp. $11,12,13,14$ ), when lowering PBR thickness (Exp. 5, 10) or increasing PFD (Exp. 1, 2, 4, 5). As shown later, all those conditions lead to FA accumulation. Obviously, an increase in the stress factor does not guarantee FA accumulation, as chlorophyll to carotenoids ratio is also subjected to change in illumination conditions (photoacclimation process). But, because of the significant effect of nitrogen starvation on both chlorophyll decrease and FA accumulation, the "stress factor" can be regarded as a useful practical indicator to monitor culture evolution during nitrogen starvation, by relating a direct and relevant primary effect of a successful nitrogen starvation, which is pigments modification. It must be noticed that chlorophyll content per DW could also be used but this has two drawbacks: an important sampling for DW concentration measurement and a time delay to obtain the DW concentration (drying period around $12-24 \mathrm{~h}$ ).

\subsection{TG-FA accumulation and role of light transfer conditions}

It is well-known that nitrogen starvation trigger FA accumulation (Tornabene et al., 1983). Biodiesel application requests however to distinguish TG-FA from other TL-FA (named "Non TG-FA" in the following, here defined as the difference between TL-FA and TG-FA). The final contents of TL-FA, TG-FA and "Non TG-FA" concentrations are given in Table 2. Except for cases with high nitrogen concentration, high initial biomass or high PBR thickness (Exp.7, 8, 9, 10, 13 and 14), TL-FA final contents are nearly constant (49-53\%) whatever starvation protocols. TG-FA final content was found however more sensitive to starvation protocol, with values ranged from $31 \%$ to $43 \%$. As a direct consequence of FA accumulation, composition of microalgae is deeply modified. Table 2 presents biomass without its FA content (represented by the difference between DW and TL-FA concentrations). Values are ranged from $33 \%$ to $76 \%$, emphasizing great modifications in biochemical composition of algae. This was already observed in Pruvost et al. (2011b), nitrogen starvation resulting in an increase in total sugar contents and a decrease in protein content (not measured here).

Depending on starvation conditions, different kinetics of FA accumulations were found. TG-FA synthesis (Fig. 2) was delayed in progressive starvation because of the progressive shift in cell metabolism, with initial nitrogen concentration determining the duration of the first standard growth phase which therefore delays starvation appearance then triggering the TG-FA synthesis. In sudden starvation, TG-FA synthesis started at the beginning of experiments (Fig. 2) as standard growth was not allowed.

Interestingly, all of the obtained results indicate a direct influence of the light received per cell on lipid accumulation. This aspect was mentioned by authors in their previous studies (Pruvost et al., 2009) but not clearly demonstrated. For sudden starvation (Exp. 11, 12, 13, 14), maximum TG-FA content (Table 2) was found around $43 \%$ for low initial biomass $\left(0.23\right.$ and $\left.0.41 \mathrm{~kg} \mathrm{~m}^{-3}\right)$ and around $14 \%$ for higher initial biomass $\left(0.62\right.$ and $\left.0.76 \mathrm{~kg} \mathrm{~m}^{-3}\right)$. For

Table 2

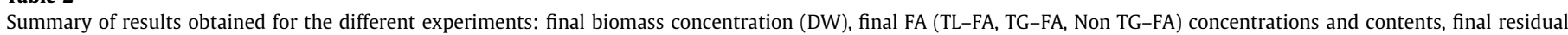
biomass contents (DW-TL), maximal TG-FA surface productivities $\left(\mathrm{S}_{\mathrm{TG}}\right)$.

\begin{tabular}{|c|c|c|c|c|c|c|c|c|c|c|c|c|c|c|}
\hline Experiment & No. 1 & No. 2 & No. 3 & No. 4 & No. 5 & No. 6 & No. 7 & No. 8 & No. 9 & No. 10 & No. 11 & No. 12 & No. 13 & No. 14 \\
\hline $\mathrm{DW}\left(\mathrm{kg} \mathrm{m}^{-3}\right)$ & 0.95 & 1.20 & 1.47 & 1.13 & 1.41 & 1.73 & 2.01 & 2.01 & 0.6 & 0.91 & 0.95 & 1.46 & 2.18 & 2.66 \\
\hline TG-FA $\left(\mathrm{kg} \mathrm{m}^{-3}\right)$ & 0.39 & 0.44 & 0.62 & 0.41 & 0.44 & 0.55 & 0.64 & 0.56 & 0.15 & 0.24 & 0.41 & 0.62 & 0.31 & 0.39 \\
\hline$(\mathrm{TG}-\mathrm{FA}) / \mathrm{DW}(\%)$ & 40.6 & 36.7 & 41.9 & 36.2 & 31.3 & 31.6 & 31.9 & 27.9 & 25.3 & 26.0 & 43.2 & 42.5 & 14.3 & 14.7 \\
\hline (Non TG-FA)/DW (\%) & 12.1 & 13.6 & 12.8 & 13.5 & 21.4 & 17.7 & 0.0 & 5.3 & 34.0 & 13.3 & 7.0 & 8.6 & 10.8 & 4.6 \\
\hline (LT-FA)/DW (\%) & 52.7 & 50.3 & 54.7 & 49.8 & 52.7 & 49.3 & 31.2 & 33.2 & 59.3 & 39.3 & 50.2 & 51.0 & 25.1 & 19.3 \\
\hline$(\mathrm{DW}-\mathrm{TL}) / \mathrm{DW}(\%)$ & 44.9 & 48.0 & 48.4 & 48.4 & 45.8 & 49.6 & 68.3 & 66.2 & 38.2 & 60.3 & 37.0 & 33.5 & 69.1 & 76.0 \\
\hline$S_{\mathrm{TG}}\left(10^{-3} \mathrm{~kg}_{\mathrm{TG}-\mathrm{FA}} \mathrm{m}^{-2} \mathrm{~d}^{-1}\right)$ & 1.7 & 2.3 & 2.6 & 2.6 & 2.4 & 2.9 & 2.1 & 2.1 & 1.1 & 1.3 & 2.6 & 3.6 & 1.6 & 1.4 \\
\hline
\end{tabular}



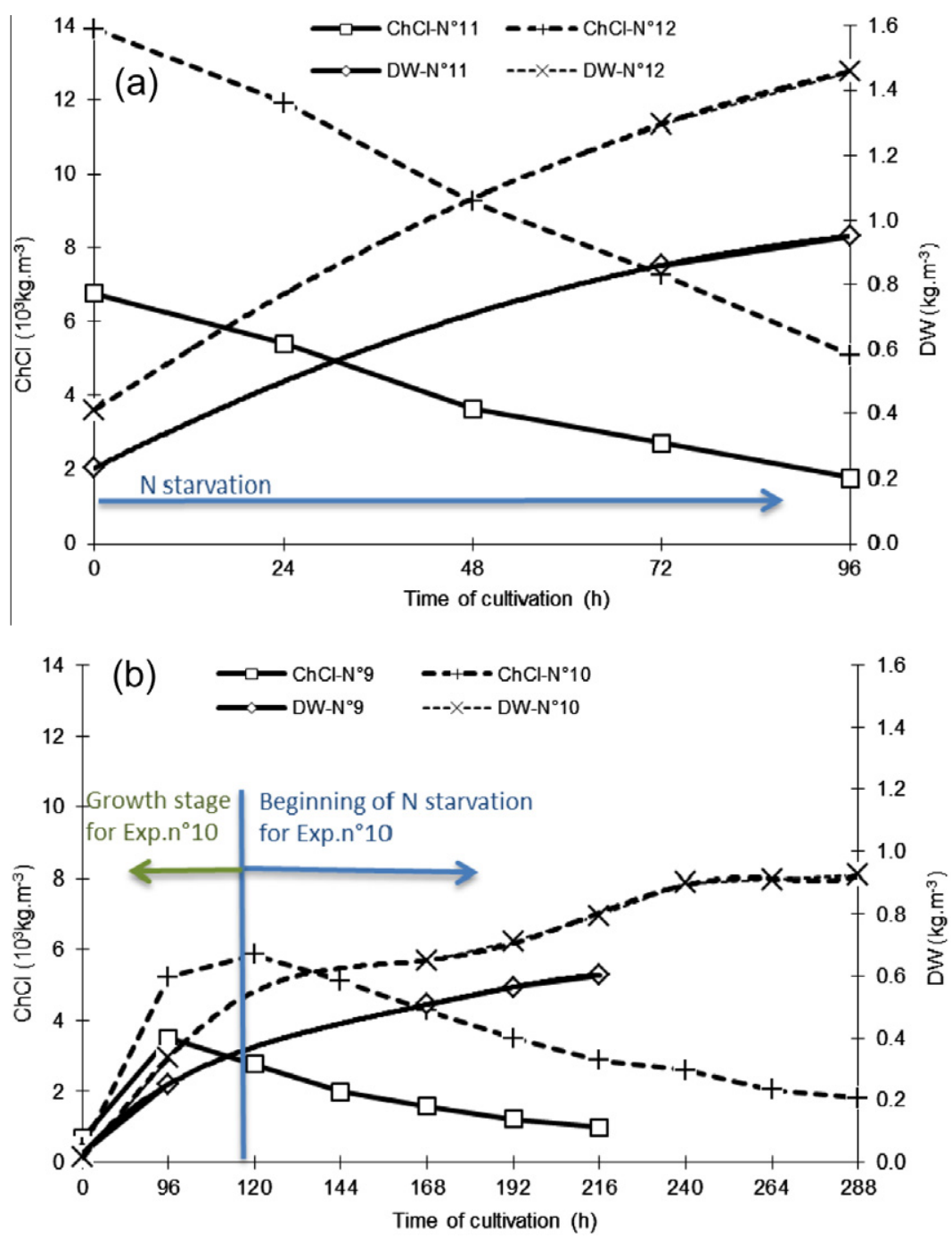

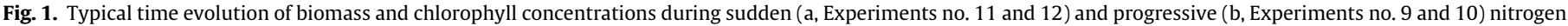
starvation.

progressive starvation with same PBR thickness and PFD (Exp. 4, 5, $6,7,8)$, TG-FA content was comprised between 31 and $36 \%$ for the five lower initial nitrogen concentrations $(0.99-2.96 \mathrm{mM})$ and $28 \%$ for the higher one $(3.61 \mathrm{mM})$. Because in progressive starvation the initial nitrogen concentration fixes the increase in biomass concentration before starvation occurs, those results emphasize the role of light attenuation conditions on TG-FA synthesis. Both protocols were found here in accordance. For the progressive one, the TGFA lowest content was obtained for the highest initial nitrogen concentration $(3.61 \mathrm{mM})$. Considering $10 \%$ nitrogen content in $N$. oculata, $3.61 \mathrm{mM}$ of nitrogen would allow a biomass synthesis of $0.5 \mathrm{~kg} \mathrm{~m}^{-3}$. This is an intermediate value between the 0.41 and $0.62 \mathrm{~kg} \mathrm{~m}^{-3}$, for which TG-FA synthesis was found also low in the case of sudden deprivation. In the opposite, for all experiments, the highest TG-FA content was always obtained when the lowest biomass concentration was achieved in starvation conditions. This is confirmed when considering the effect of PBR thickness, TG-FA content decreasing when increasing PBR thickness (Fig. 3). Because an increase in PBR thickness also increases light attenuation, this emphasises the need to provide sufficient light per cell in addition to nitrogen starvation condition.

The relevance in FA accumulation of the light received per cell in addition to nitrogen starvation is obviously not surprising, as
FA accumulation is promoted when stopping cells division but also requests light energy for FA photosynthesis. This has however several consequences and especially from the practical point of view, as the light received per cell is the result of several aspects that are not easy to control. Light attenuation conditions are indeed affected by the PBR geometry (e.g. PBR thickness) but also biomass concentration (related to initial nitrogen concentration in progressive starvation) and pigments composition (strongly modified during nitrogen starvation). Obviously, PFD also affects directly light received per cell. It would be interesting in this regards to deeper investigate its specific influence, PFD values investigated here being comprised in a limited range of variation (160$250 \mu$ mole $\mathrm{m}^{-2} \mathrm{~s}^{-1}$ ). As for example, TG-FA content was found to slightly decrease from $40.6 \%$ to $36.2 \%$ when increasing PFD. In first instance, this could be stated as a disagreement with previous remarks. But it should be noticed that higher light intensity results also in a higher DW biomass concentration $\left(0.95-1.13 \mathrm{~kg} \mathrm{~m}^{-3}\right)$, affecting thus the light transfer conditions here in a negative way. This means once again that TG-FA synthesis cannot be dissociated from biomass production as it affects light transfer conditions.

The relevance of light transfer conditions in growth kinetics of photosynthetic microorganisms is well-known and authors have 

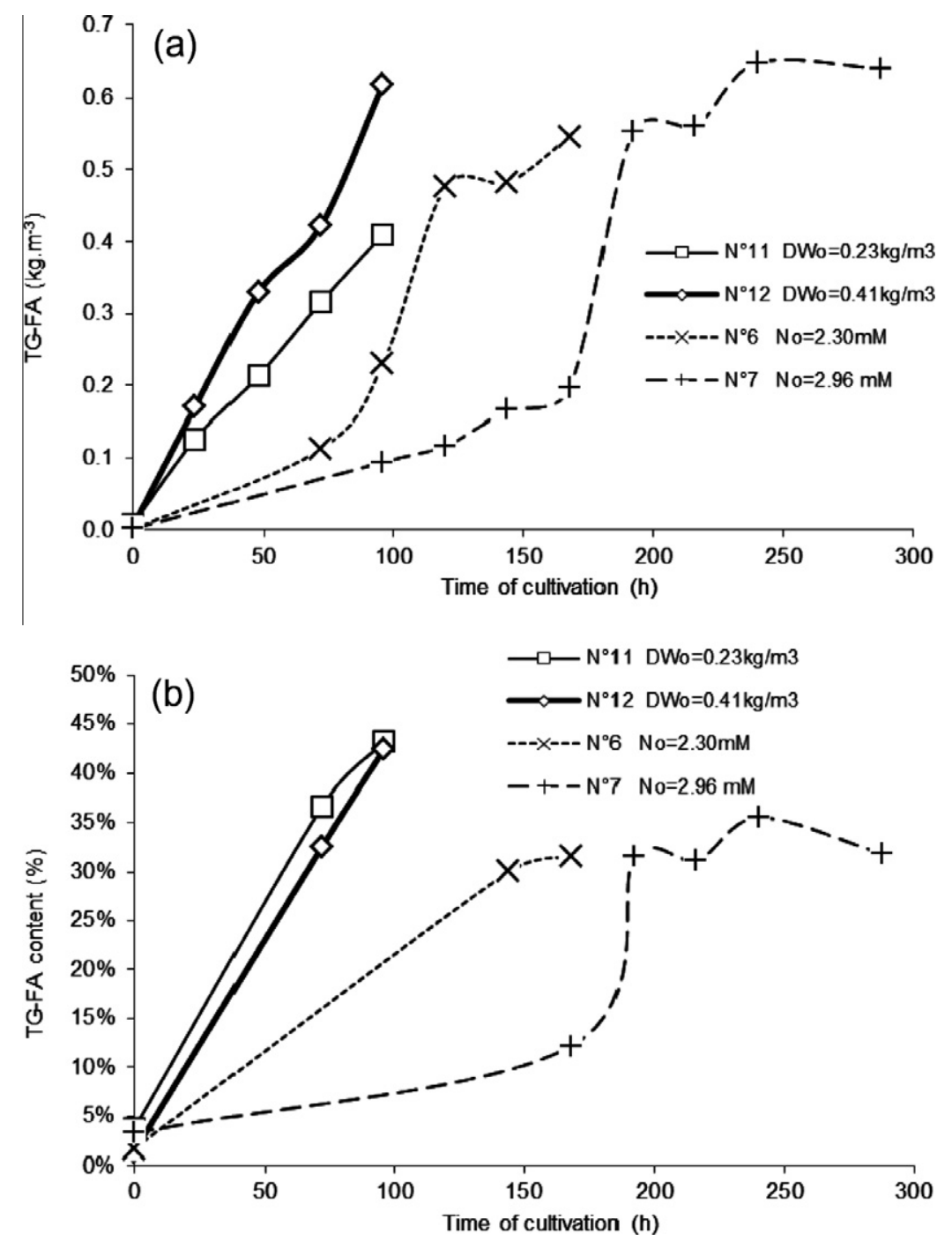

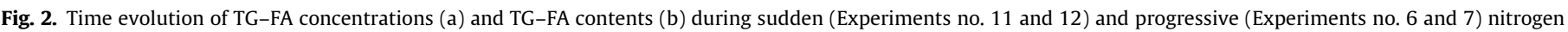
starvation.

shown recently their direct impact on biomass productivity (Takache et al., 2010) or, more specifically, hydrogen production which was obtained on Chlamydomonas reinhardtii with sulphur deprivation protocol (Degrenne et al., 2011; Fouchard et al., 2009). In both cases, theoretical approaches introducing radiative transfer modelling revealed especially interesting. It allows linking evolution of light transfer conditions and their impact on the photosynthetic growth. When combined to a nutrient starvation modelling which also affects growth (like sulphur or nitrogen deprivation for hydrogen and lipids production respectively), this could serve in the optimization of culture protocols, the respective roles of each parameter (light received per cell, nutrient limitation) on biological responses being then represented (assuming appropriate models to be established). Photosynthetic hydrogen production modelling was for example used to define progressive sulphur deprivation protocols. Initial sulphur concentration and PFD were defined in order to optimize in two successive steps biomass and starch accumulation followed by anoxic conditions to induce hydrogen release. Methodology is thus almost similar to the present case of triggering FA accumulation with nitrogen deprivation. The combined effects of nutrient starvation and light transfer conditions on biomass growth and cells metabolism (starch or FA accumulation) are indeed encountered in both lipids and hydrogen inducing protocols. Main differences are (i) anoxic conditions which are obviously not required for FA accumulation, (ii) the sulphur effect on PSII activity reduction not involved in FA accumulation, and (iii) the strong effect of nitrogen starvation on pigments degradation in FA accumulation that progressively modifies light transfer conditions during starvation (sulphur deprivation has a negligible influence in this regards). All of those features could be considered with a slight modification of already developed models. Experimental results obtained in this study will be of high interest for that purpose.

\subsection{Fatty acids and biodiesel requirements}

TG-FA profiles are given in Table 3a. Under normal physiological culture conditions, TG-FA are in low proportions (around 2-3\% of DW) and have a simple composition with $\mathrm{C} 16: 0$ and $\mathrm{C} 16: 1 \mathrm{n}-7$ accounting each for about $45 \%$ of total TG-FA mass. This results in an unsaturation degree of TG-FA around 0.5. For conditions leading to an important TG-FA accumulation (nitrogen starvation, high light received per cell), TG-FA composition was found rather constant whatever protocols (progressive or sudden nitrogen starvation), with a composition and unsaturation degree almost similar to the one obtained in standard growth conditions. Typical TGFA profile evolutions are given in Fig. 4 for each starvation protocol. 

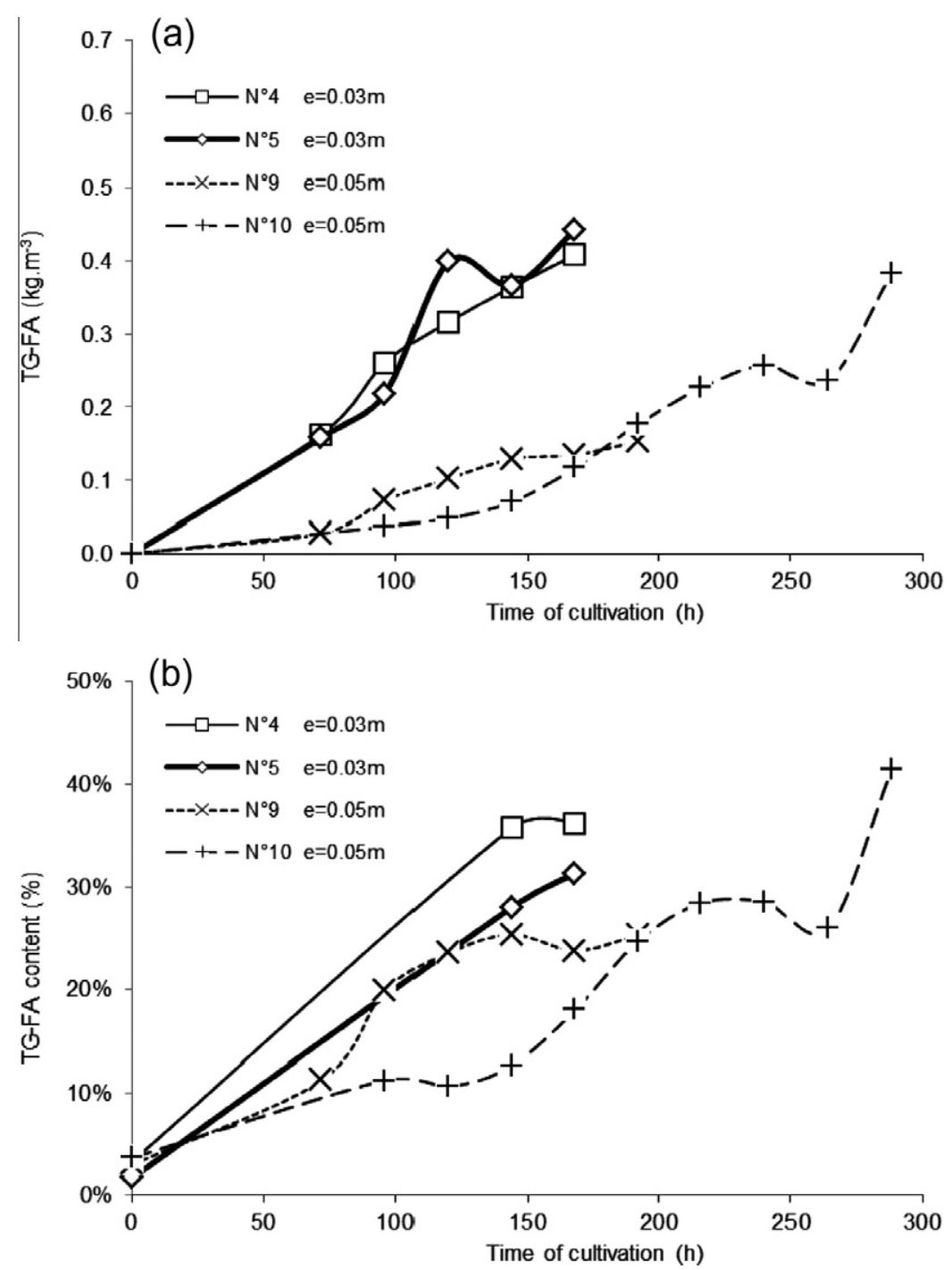

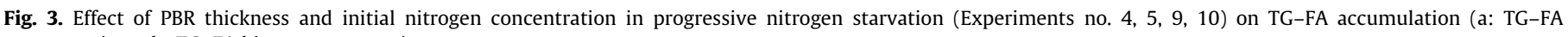
concentrations; b: TG-FA biomass contents).

Table 3

Typical FA compositions obtained under standard culture conditions (a) and after nitrogen starvation (b) leading to non-optimized conditions of high light received per cell (high initial nitrogen concentration, Experiments no. 7 and 8).

\begin{tabular}{|c|c|c|c|c|c|c|c|c|}
\hline & \multicolumn{2}{|c|}{$\mathrm{C} 14: 0$} & \multicolumn{2}{|c|}{ C16:0 } & \multicolumn{2}{|c|}{ C16:1n-7 } & $C 20: 5 n-3$ & Misc. \\
\hline \multicolumn{9}{|l|}{ (a) } \\
\hline TL-FA (\%) & \multirow[t]{2}{*}{7} & \multirow{2}{*}{\multicolumn{3}{|c|}{$\begin{array}{l}26 \\
45\end{array}$}} & 29 & \multicolumn{2}{|c|}{28} & 10 \\
\hline \multirow[t]{2}{*}{ TG-FA (\%) } & & & & & 45 & & & 10 \\
\hline & C16:0 & C1 & $5: 1 n-7$ & & $8: 1 \mathrm{n}-9$ & C18:2n-6 & C18:3n-3 & Misc. \\
\hline \multicolumn{9}{|l|}{ (b) } \\
\hline TL-FA (\%) & 35 & 21 & & 21 & & 5.5 & 5.5 & 12 \\
\hline TG-FA (\%) & 36 & 22 & & 22 & & 5 & 5 & 10 \\
\hline
\end{tabular}

Main differences compared to standard growth were an important decrease of $\mathrm{C} 16: 1 \mathrm{n}-7$ (45\% to around $30 \%$ ) and an increase of C18:1n-9 in slight proportions (3\% to around $8 \%$ ). Compared to higher plants, TG-FA from $N$. oculata revealed to be more saturated than TG-FA from rapeseed, soybean or sunflower, but almost similar to palm oil (C16:0 46.4\%-C18:1 41.2\% (Aranda et al., 2008)). Regarding biodiesel application, this would result in a higher freezing point and a higher stability to oxidation but high PUFA content (1.7-3.5\% for only C20:4n-6 and C20:5n-3) would however decrease significantly that stability.
As shown in previous sections, some experiments leading to nitrogen starvation but with low light received per cell (high absorption) resulted in intermediate or low FA accumulation. This is case for example when applying too high initial nitrogen concentration in progressive starvation. In addition to a lower TG-FA content as discussed previously, corresponding profiles were found rather different with decrease of $\mathrm{C} 16: 0$ and $\mathrm{C} 16: 1 \mathrm{n}$ 7 and increase of $\mathrm{C} 18: 1 \mathrm{n}-9, \mathrm{C} 18: 2 \mathrm{n}-6$ and C18:3n-3 (Table 3b). This could indicate (i) a partial FA maturation compared to successful starvation or (ii) differences in TG-FA metabolic pathways due for example to the different light received per cell. Analysis are here insufficient to conclude but regarding biodiesel application, it has to be mentioned a slight modification of the unsaturation level (here not in the favour of biodiesel norms). This also again illustrates the need to control culture conditions to optimise both quantity and quality of TG-FA.

\subsection{Total and non TG fatty acids evolutions}

Under normal physiological culture conditions, TL-FA which represent between 8 to $12 \%$ of DW are mainly C16:1n-7, C20:5n-3, $\mathrm{C} 16: 0$ and $\mathrm{C} 14: 0$ (Table 3 ). This FA composition led to an unsaturation degree comprised between 1.8 and 2.1. As TG-FA content is 
low, most of these FA are membranes constituents. During nitrogen starvation, modification of TL-FA composition is mainly the consequence of TG-FA high increase but also, in a lesser extent, of "Non TG-FA" composition modifications. During nitrogen starvation, proportion of C20:5n-3 in "Non TG-FA" decreases whereas those of C16:0 and $C 18: 1 n-9$ increase, $C 16: 1 n-7$ proportion staying constant (Fig. 4). As a result, "Non TG-FA" profile tends towards TG-FA profile. Consequently, unsaturation degree of "Non TG-FA" shows a marked decrease, with minimal values reaching 0.8-1.6.

"Non TG-FA" concentration increases during both progressive and sudden nitrogen starvations (Fig 5), but in a lesser extent than TG-FA, with a content comprised between $5.7 \%$ and $20 \%$ of the DW (to be compared to $14-43 \%$ for TG-FA). An exception occurs in experience 9 with a "Non TG-FA" content of 34\%. This experiment show also a low chlorophyll concentration associated with a low biomass concentration and a high PBR thickness $(0.055 \mathrm{~m})$. This could indicate that TG-FA synthesis pathway was able to start but was then stopped before TG-FA significant accumulation, due to a too low light received per cell. This tends to be confirmed in experiment 10 (same thickness and PFD, but initial nitrogen concentration was increased from 0.93 to $1.65 \mathrm{mM}$ ). Starvation and "Non TG-FA" synthesis occur, but cells do not receive enough light for significant TG-FA synthesis. This conclusion has however to be considered with attention as FA analysis do not allow here separating glycolipids and phospholipids, both being measured simultaneously as "Non TG-FA". A full lipidomic analysis would provide here more detailed information.

\subsection{TG-FA productivity}

This is obvious that TG-FA productivity is a key-criterion for biodiesel production. Increasing TG-FA content does not necessar-
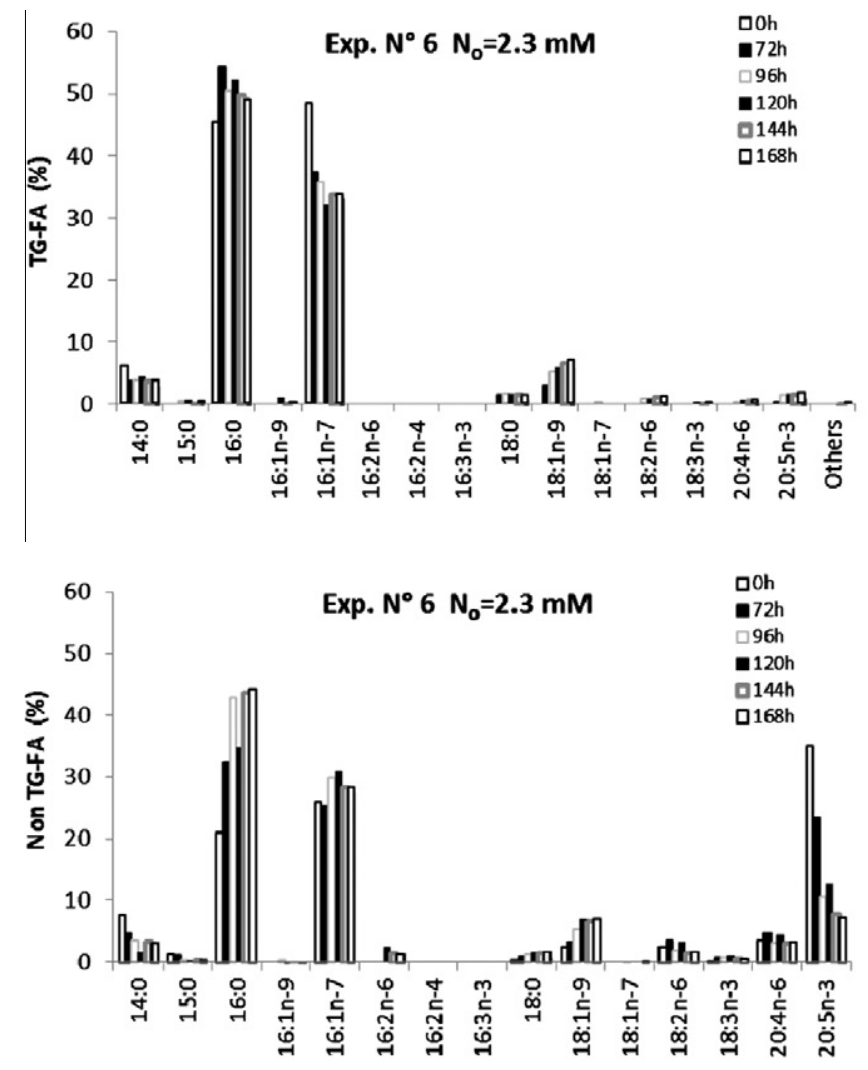

ily results in high TG-FA productivity because of the simultaneous decrease in kinetics induced by nitrogen starvation. As the final goal is to achieve solar outdoor production, productivity was here calculated in terms of areal productivity based on the illuminated surface. For a flat panel PBR, TG-FA areal productivity is then obtained from:

$S_{\mathrm{TG}}=\frac{[\mathrm{TG}]_{T}-[\mathrm{TG}]_{T_{\mathrm{o}}}}{T-T_{\mathrm{o}}} \times \frac{V_{\mathrm{r}}}{S}=\frac{[T G]_{T}-[T G]_{T_{\mathrm{o}}}}{T-T_{\mathrm{o}}} \times e$

$[\mathrm{TG}]_{T}$ is the concentration of TG-FA at time $T$, $e$ the PBR thickness, $V_{\mathrm{r}}$ the culture volume and $\mathrm{S}$ the PBR illuminated surface $\left(V_{\mathrm{r}}=\mathrm{Se}\right) . T_{\mathrm{o}}$ represents the beginning of production. Because in progressive starvation, biomass growth and lipids accumulation are conducted in the same operating stage, $T_{\mathrm{o}}$ is trivially defined as the beginning of cultivation (PBR inoculation). In sudden starvation, the time to obtain the initial biomass concentration which is applied at the beginning of sudden starvation experiment has to be added. This was here calculated using biomass productivity of the continuous PBR used to obtain biomass for starvation experiments $\left(0.35 \mathrm{~g} \mathrm{~d}^{-1}\right)$. For example, to obtain the initial DW biomass concentration $\mathrm{DW}_{\mathrm{o}}=0.23 \mathrm{~kg} \mathrm{~m}^{-3}$ in Exp.11, a continuous production during 0.65 day was necessary.

Comparing sudden and progressive starvation protocols leads to interesting conclusions. In sudden starvation (Fig. 6a), productivity is found almost constant with time, higher initial biomass concentrations resulting in lower productivities (Exp.13 and 14). Maximum productivity is obtained for an intermediate initial biomass $\left(D_{\mathrm{o}}=0.41 \mathrm{~kg} \mathrm{~m}^{-3}\right.$, Exp.12). PFD being the same, this again emphasizes the effect on productivity of the light received per cell which affects TG-FA synthesis, resulting in an optimum of initial DW concentration to be found. Same conclusion can be drawn
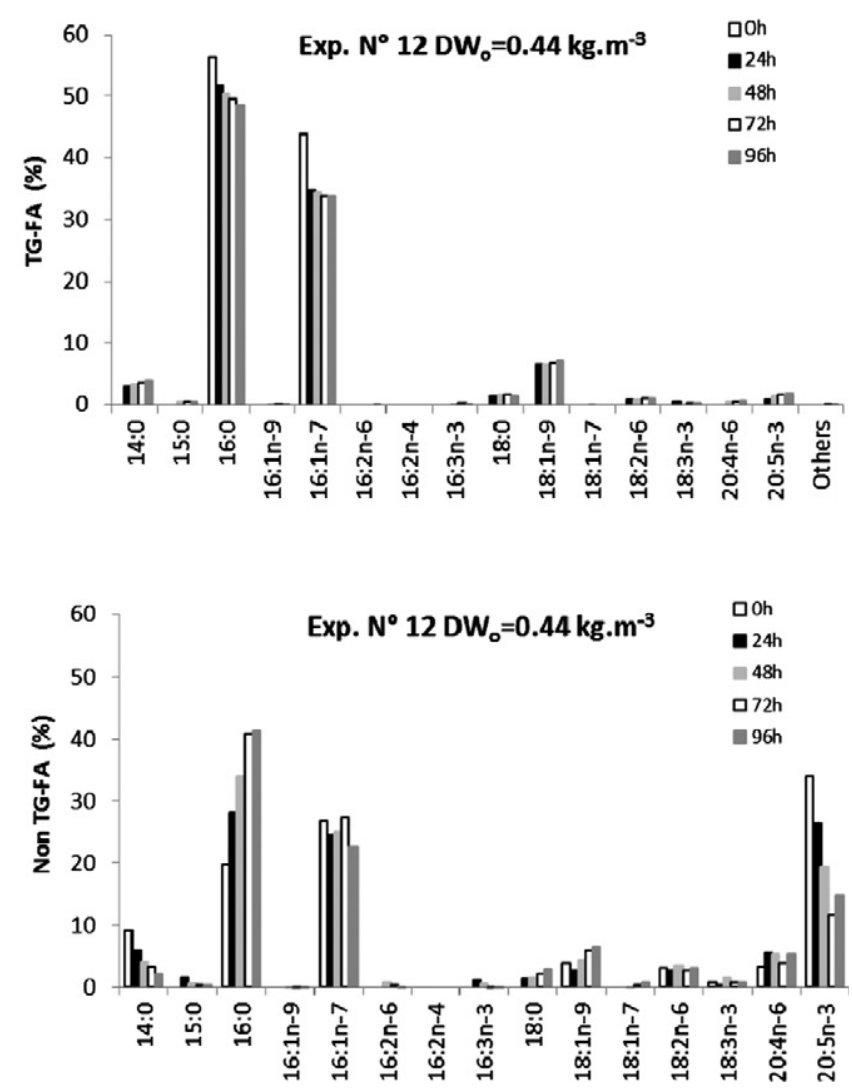

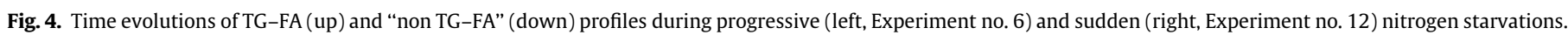


for progressive starvation (Fig. 6b), but with initial nitrogen concentration $\mathrm{N}_{\mathrm{O}}$ as the operating parameter. Because initial nitrogen directly affects the DW concentration evolution during the experiment, and thus light transfer conditions, there is an optimum initial nitrogen concentration $\left(\mathrm{N}_{\mathrm{o}}=2.3 \mathrm{mM}\right.$, Exp.6) leading to a maximal value of TG-FA productivity. As another consequence, the time to achieve maximum TG-FA productivity for a given production increases also with increasing initial nitrogen concentration, because of the longer initial growth phase then induced. It must be noticed both starvation protocols results are in accordance. Because of the low culture volume $(1 \mathrm{~L})$ limiting sampling rate, the DW biomass concentration was not measured for progressive starvation. But considering $10 \%$ nitrogen content in N. oculata, $2.3 \mathrm{mM}$ of nitrogen would allow theoretically a maximum DW biomass synthesis of $0.32 \mathrm{~kg} \mathrm{~m}^{-3}$, which is close to the biomass leading to maximum productivity in case of sudden starvation $\left(\mathrm{DW}_{\mathrm{o}}=0.42 \mathrm{~kg} \mathrm{~m}^{-3}\right)$.

Maximum TG-FA productivities $S_{\mathrm{TG}}$ are compared in Table 2 for all experiments. The need of a compromise in the DW biomass concentration during nitrogen starvation is here emphasized. In sudden starvation, the highest TG-FA productivity $\left(3.6 \times 10^{-3} \mathrm{~kg}_{\mathrm{TG}}-\right.$
FA $\left.\mathrm{m}^{-2} \mathrm{~d}^{-1}\right)$ is obtained in Exp. 12 for an intermediate biomass concentration ( $D W=1.46 \mathrm{~kg} \mathrm{~m}^{-3}$ ) for which a TG-FA accumulation of $42.5 \%$ is reached. A highest TG-FA accumulation is achieved in Exp.11 (43.2\%) but for a lower biomass concentration $\left(\mathrm{DW}=0.95 \mathrm{~kg} \mathrm{~m}^{-3}\right)$, resulting in lower productivity $\left(2.6 \times 10^{-3-}\right.$ $\left.\mathrm{kg}_{\mathrm{TG}-\mathrm{FA}} \mathrm{m}^{-2} \mathrm{~d}^{-1}\right)$. Exp.13 and 14 result in higher biomass concentrations ( $\mathrm{DW}>2 \mathrm{~kg} \mathrm{~m}^{-3}$ ) but with significantly reduced TG-FA contents (around 14-15\%). Corresponding TG-FA productivity (around $1.5 \times 10^{-3} \mathrm{~kg}_{\mathrm{TG}-\mathrm{FA}} \mathrm{m}^{-2} \mathrm{~d}^{-1}$ ) is then found more than 2-fold below the maximal observed.

Progressive starvation experiments again confirm the effect of the light received per cell in TG-FA accumulation. The maximum TG-FA productivity is obtained in Exp.6 $\left(2.9 \times 10^{-3} \mathrm{~kg}_{\mathrm{TG}-\mathrm{FA}} \mathrm{m}^{-2} \mathrm{~d}^{-1}\right)$ with a TG-FA content of $31.6 \%$ and a maximal DW biomass concentration of $1.7 \mathrm{~kg} \mathrm{~m}_{-3}$. By achieving a lower DW concentration as in Exp.3, a higher TG-FA content is observed, close to the maximal value reported in sudden starvation (41.9\%). The resulting TG-FA is however found slightly lower than in Exp.6 $\left(2.6 \times 10^{-3} \mathrm{~kg}_{\mathrm{TG}-\mathrm{FA}}\right.$ $\mathrm{m}^{-2} \mathrm{~d}^{-1}$ vs. $2.9 \times 10^{-3} \mathrm{~kg}_{\mathrm{TG}-\mathrm{FA}} \mathrm{m}^{-2} \mathrm{~d}^{-1}$ ), emphasizing again the particular role of DW concentration in the process. For a given TG-FA content, DW concentration should have been maximized to
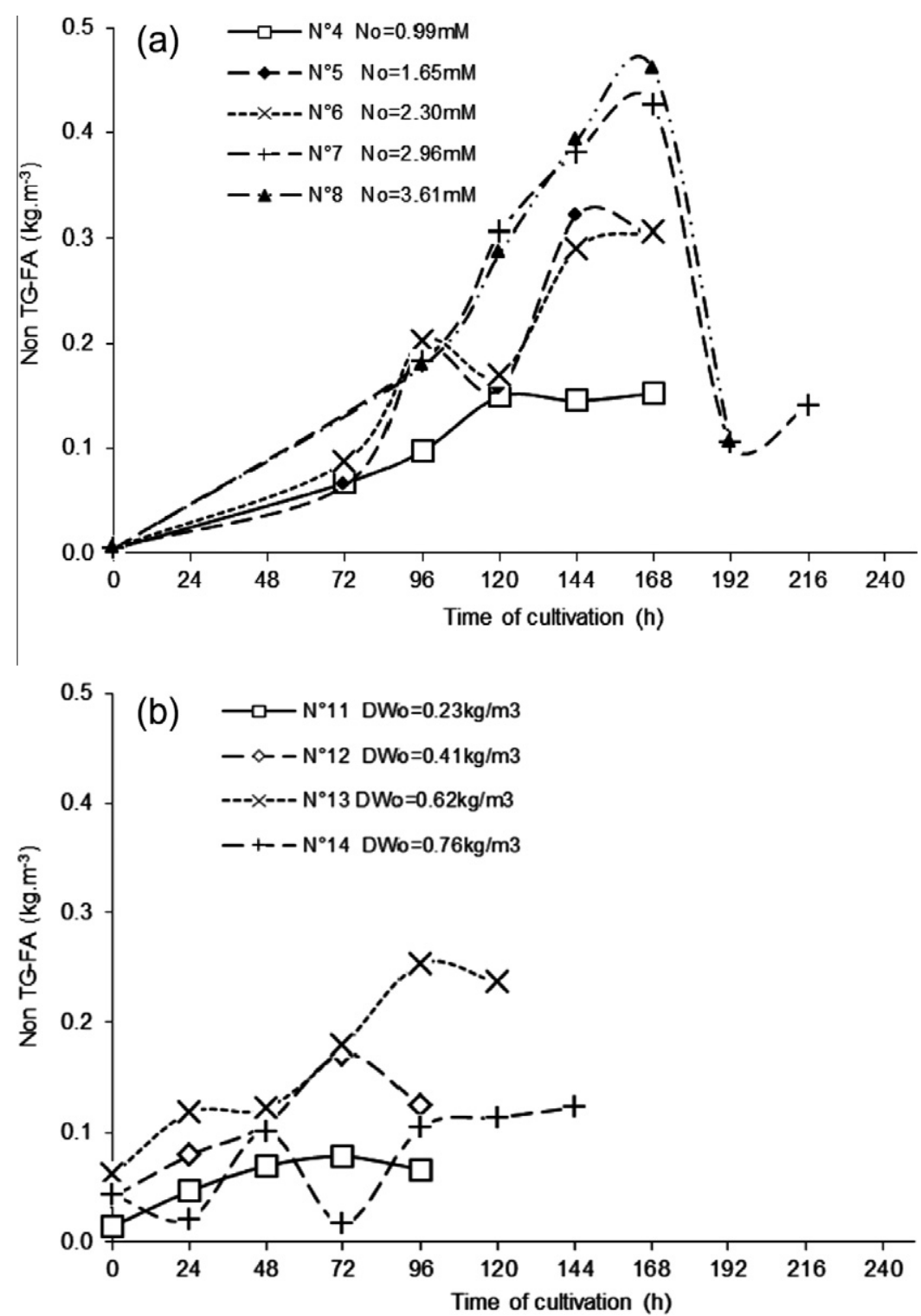

Fig. 5. Time evolution of Non TG-FA concentrations for progressive (a, Experiments no. 4, 5, 6, 7, 8) and sudden nitrogen starvation (b, Experiments no. 11, 12, 13, 14) 
increase TG-FA production in the PBR. However, increasing DW concentration reveals here to have a negative effect on TG-FA accumulation in cells (lower light received per cell). This clearly makes light received per cell a key parameter of the process, in addition to nitrogen starvation.

\subsection{Practical biodiesel production: optimisation of light transfer conditions and sudden vs. progressive starvation protocol}

Our results have emphasized the need to provide a high amount of light received per cell in addition to nitrogen starvation in order to trigger significant TG-FA accumulation. The light received per cell is fully dependent on incident PFD, biomass optical properties and concentration, and PBR geometry (especially its depth of culture). All of these features can be controlled and optimised using radiative transfer modelling but, in a general manner, increasing the light received per cell implies to work at low biomass concentration and/or with low culture depth to decrease shading and light attenuation effect. Algae optical properties will be here also especially relevant. Light transmission can also be increased by decreasing light harvesting complex in cells ("small antennae mutants"). Regarding this last possibility, it must however be noticed that pigment degradation is already one of the major effect of nitrogen starvation. Although the interest of small antennae mutants was already proven regarding light transmission, its interest in terms of lipids production remains to be checked (the interest on biomass production only which implies full light absorption is not obvious, see Pruvost et al., 2011a for example).

The need to apply nitrogen starvation makes interesting the two-step process, in which biomass is first produced in optimal cultivation conditions (growing stage) before it is sent in a specific system where nitrogen starvation occurs (oil-producing stage). This solution was discussed in numerous studies (see for example Rodolfi et al., 2009). Our results tend to emphasize the additional role of the light received per cell which has to be high. This can be achieved in different ways. For example, culture dilution can be applied before entering the oil-producing stage. It must be noticed this would be also beneficial regarding the decrease in nitrogen concentration. Such solution was proved for example efficient in the case of hydrogen production induces by sulphur deprivation
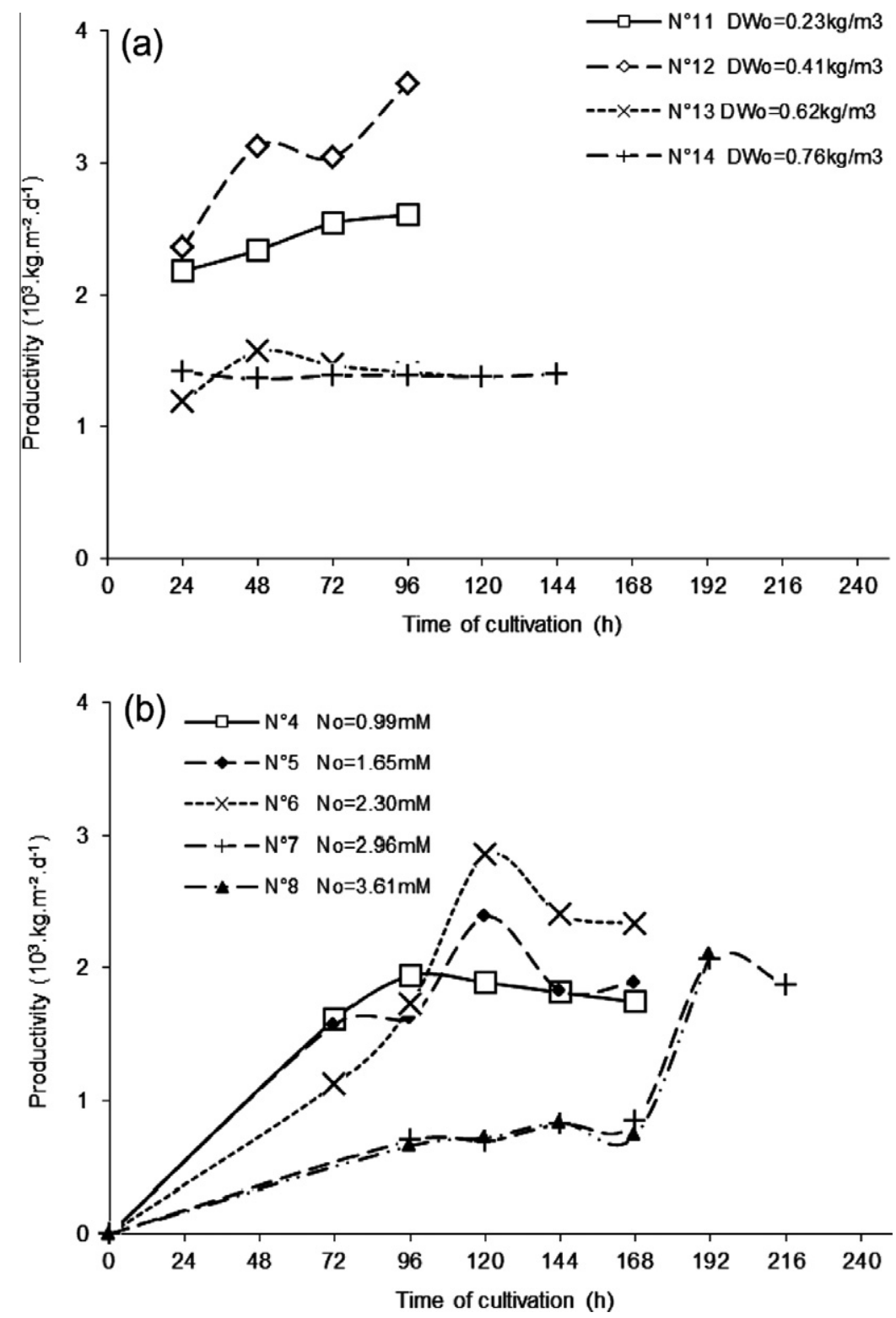

Fig. 6. Time evolution of TG-FA productivities for sudden (a, Experiments no. 11, 12, 13, 14) and progressive nitrogen starvation (b, Experiments no. 4, 5, 6, 7, 8). 
(Laurinavichene et al., 2002). But other strategies can be applied, such as a higher sunlight collection in the cultivation system used for the oil-producing stage, or a different culture depth to decrease light attenuation effect. Whatever the case, this is obvious that the role of the light received per cell could have several consequences for practical application, and it remains thus to be more investigated.

In our study, we investigated both sudden and progressive starvation protocols. Regarding practical application, the progressive starvation protocol should have to be promoted. The application at industrial large scale of sudden starvation will indeed be more costly, because of the need of an extra harvesting step and more labour intensive operations to re-suspend cells in a medium deprived in nitrogen. In our studies, lower TAG productivities were however achieved for progressive starvation protocol. This is not surprising as, in sudden starvation protocol, biomass concentration is set at the beginning of the experiment and remains then almost constant, making easier optimisation of the process (especially with respect to light received per cell). In progressive starvation, all parameters evolve with time and interact in a complex manner.

It must however be noticed that higher productivities for progressive starvation protocol could certainly be expected than the ones reported in this study. This was for example proven that high TG-FA content could be achieved. Although the finding of optimised conditions will be certainly complex, it could thus be expected that their fine tuning could allow optimising both TG-FA and DW biomass concentration accumulation to maximize TG-FA productivity.

Obviously, our lab-scale conditions are far from the ones encountered in large scale outdoor application. Solar conditions will make especially PFD highly variable. The influence of day-night cycles for example is a problem on its own. As investigated by authors but only for biomass production, outdoor production results in a transient behaviour of the cultivation system, fully linked to PFD time evolution (Pruvost et al., 2011a, 2012). Regarding our results achieved in continuous light which emphasized the relevance of the light received per cell on lipids accumulation during nitrogen starvation, this is obvious that the optimisation in daynight cycles will be more complex, especially in the context of progressive starvation which appears as the sole reasonable strategy that could be applied in full scale. This reinforces the need of further investigating progressive starvation protocol although it would be more complex in terms of representation and optimisation. Modelling would be here certainly of primary interest. As it was shown in sulphur deprivation and hydrogen production (Degrenne et al., 2011), modelling approach was found useful for the optimisation of strongly interrelated and time evolving parameters (considering in addition that biomass, TG-FA and pigments, which affect light received per cell, have certainly different dynamics, making more difficult their respective optimisation). This could serve as a basis to define advanced control strategies dedicated to oil-producing protocols that could be then implemented at large outdoor scale.

\section{Conclusion}

In addition to the marked effects of nitrogen starvation, light received per cell was found to deeply affect TG-FA synthesis. Up to a 2 -fold increase in productivity was found with appropriate conditions, with maximal productivities of $3.6 \times 10^{-3} \mathrm{~kg}_{\mathrm{TG}-\mathrm{FA}} \mathrm{m}^{-2} \mathrm{~d}^{-1}$ and $2.8 \times 10^{-3} \mathrm{~kg}_{\mathrm{TG}-\mathrm{FA}} \mathrm{m}^{-2} \mathrm{~d}^{-1}$ for sudden or progressive starvation respectively (PFD of $250 \mu$ mole $\mathrm{m}^{-2} \mathrm{~s}^{-1}$ ). This was found also beneficial to TG-FA profile although PUFA presence would impair biodiesel stability.

Future studies will develop modeling approaches for a combined optimization of nitrogen deprivation and light received per cell. This appears indeed as a prerequisite for outdoor optimization because of the dynamic regime then induced by day/night cycles.

\section{Acknowledgements}

This work was supported by the French research program CNRS-LIPALG and the French National Research Agency project DIESALG (ANR-12-BIME-0001-02). Support was also provided by the HélioBiotec platform, funded by the European Union (European Regional Development Fund), the Région Provence Alpes Côte d'Azur, the French Ministry of Research, and the Commissariat à l'Energie Atomique et aux Energies Alternatives.

Authors thank Hélène Marec-Dechandol for PBR's data acquisition and control, and Jean-Luc Hauser for PBR realization and technical improvement.

\section{References}

Aranda, D.A.G., Santos, R.T.P., Tapanes, N.C.O., Ramos, A.L.D., Antunes, O.A.C., 2008. Acid-catalyzed homogeneous esterification reaction for biodiesel production from palm fatty acids. Catal. Lett. 122 (1-2), 20-25.

Bligh, E.G., Dyer, E.J., 1959. A rapid method of total lipid extraction and purification. Can. J. Biochem. Physiol. 37, 911.

Chisti, Y., 2007. Biodiesel from microalgae. Biotechnol. Adv. 25, 294-306.

Christie, W.W., 1989. Gas Chromatography and Lipids: A Practical Guide. The Oily Press.

Degrenne, B., Pruvost, J., Titica, M., Takache, H., Legrand, J., 2011. Kinetic modeling of light limitation and sulfur deprivation effects in the induction of hydrogen production with Chlamydomonas reinhardtii. Part II: definition of model-based protocols and experimental validation. Biotechnol. Bioeng. 108 (10), 22882299.

Flynn, K.J., Davidson, K., Cunningham, A., 1993. Relations between carbon and nitrogen during growth of Nannochloropsis oculata (Droop) Hibberd under continuous illumination. New Phytol. 152 (4), 717-722.

Folch, J., Less, M., Sloane, G.H., 1957. A simple method for the isolation and purification of total lipids from animal tissues. J. Biol. Chem. 226, 497-509.

Fouchard, S., Pruvost, J., Degrenne, B., Titica, M., Legrand, J., 2009. Kinetic modeling of light limitation and sulphur deprivation effects in the induction of hydrogen production with Chlamydomonas reinhardtii. Part I: model description and parameters determination. Biotechnol. Bioeng. 102 (1), 132-147.

Goericke, R., Welschmeyer, N.A., 1992. Pigment turnover in the marine diatom Thalassiosira weissflogii. J. Phycol. 28 (4), 498-507.

Josrgensen, E.G., 1969. The adaptation of plankton algae IV. Light adaptation in different algal species. Physiol. Plant 22 (6), 1307-1315.

Laurinavichene, T.V., Tolstygina, I.V., Galiulina, R.R., Ghirardi, M.L., Seibert, M., Tsygankov, A.A., 2002. Dilution methods to deprive Chlamydomonas reinhardtii cultures of sulfur for subsequent hydrogen photoproduction. Int. J. Hydrogen Energy 27 (11-12), 1245-1249.

Meier, S., Mjos, S.A., Joensen, H., Grahl-Nielsen, O., 2006. Validation of a one step extraction/methylation method for determination of fatty acids and cholesterol in marine tissues. J. Chromatogr. A 1104, 291-298.

Pruvost, J., 2011. Cultivation of algae in photobioreactors for biodiesel production. In: Pandey, A., Larroche, C., Ricke, S.C., Dussap, C.G. (Eds.), Biofuels: Alternative Feedstocks and Conversion Processes. E.I., USA

Pruvost, J., Van Vooren, G., Cogne, G., Legrand, J., 2009. Investigation of biomass and lipids production with Neochloris oleoabundans in photobioreactor. Bioresour. Technol. 100, 5988-5995.

Pruvost, J., Cornet, J.F., Goetz, V., Legrand, J., 2011a. Modeling dynamic functioning of rectangular photobioreactors in solar conditions. AIChE J. 57 (7), 1947-1960.

Pruvost, J., Van Vooren, G., Le Gouic, B., Couzinet-Mossion, A., Legrand, J., 2011b. Systematic investigation of biomass and lipid productivity by microalgae in photobioreactors for biodiesel application. Bioresour. Technol. 102, 150-158.

Pruvost, J., Cornet, J.F., Goetz, V., Legrand, J., 2012. Theoretical investigation of biomass productivities achievable in solar rectangular photobioreactors for the cyanobacterium Arthrospira platensis. Biotechnol. Prog. 28 (3), 699-714.

Ritchie, R.J., 2006. Consistent sets of spectrophotometric chlorophyll equations for acetone, methanol and ethanol solvents. Photosynth. Res. 89, 27-41.

Rodolfi, L., Chini Zittelli, G., Bassi, N., Padovani, G., Biondi, N., Bonini, G., Tredici, M. 2009. Microalgae for oil: strain selection, induction of lipid synthesis and outdoor mass cultivation in a low-cost photobioreactor. Biotechnol. Bioeng. 102 (1), 100-112.

Sheehan, J., Dunahay., T., 1998. A Lookback at the US Department of Energy's Aquatic Species Program: Biodiesel from Algae. U.S. Department of Energy's Office of Fuels Development

Shifrin, N.S., Chilsholm, S.W., 1981. Phytoplankton lipids: interspecific differences and effects of nitrate, silicate and light-dark cycles. J. Phycol. 17 (4), 374-384.

Siaut, M., Cuiné, S., Cagnon, C., Fessler, B., Nguyen, M., Carrier, P., Beyly, A., Beisson, F., Triantaphylides, C., Li-Beisson, Y., Peltier, G., 2011. Oil accumulation in the model green alga Chlamydomonas reinhardtii: characterization, variability between common laboratory strains and relationship with starch reserves. BMC Biotechnol. 11 (7). 
Spolaore, P., Joannis-Cassan, C., Duran, E., Isambert, A., 2006. Commercial applications of microalgae. J. Biosci. Bioeng. 101 (2), 87-96.

Strickland, J.D.H., Parsons, T.R., 1968. A Practical Handbook of Seawater Analysis: Pigment Analysis. Bulletin of Fisheries Research Board of Canada 167.

Takache, H. Christophe, G. Cornet, J.F. Pruvost, J. 2010. Experimental and theoretical assessment of maximum productivities for the micro-algae Chlamydomonas reinhardtii in two different geometries of photobioreactors. Biotechnol. Prog. 26 (2), 431-440.
Tornabene, T.G., Holzer, G., Lien, S., Burris, N., 1983. Lipid composition of the nitrogen starved green alga Neochloris oleoabundans. Enzyme Microb. Technol. 5, 435-440.

Vicente, G., Coteron, A., Martinez, M., Aracil, J., 1998. Application of the factorial design of experiments and response surface methodology to optimize biodiese production. Ind. Crops Prod. 8, 29-35.

Wijffels, R.H., Barbosa, M.J., 2010. An outlook on microalgae biofuels. Science 329 (13), 796-799. 